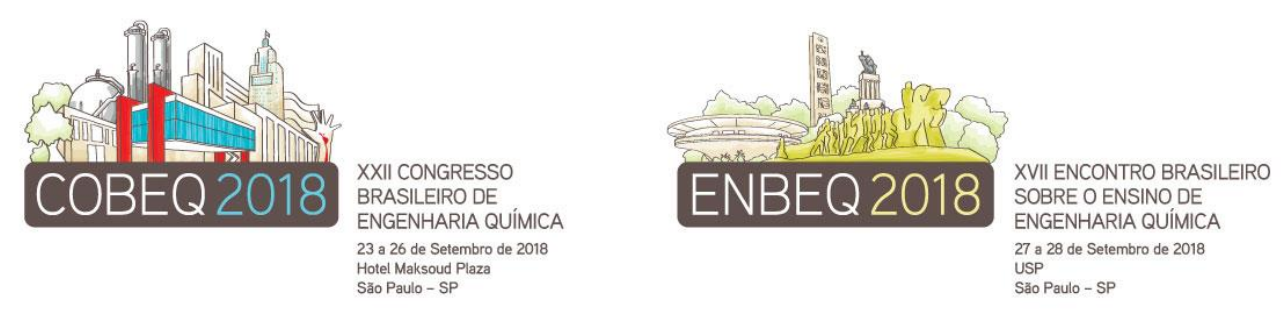

\title{
ESTUDO SOBRE A APLICAÇÃO DE TECNOLOGIAS DE INFORMAÇÃO E COMUNICAÇÃO UTILIZANDO APRENDIZAGEM BASEADA EM PROBLEMAS DISPONIBILIZADOS NO MOODLE
}

\author{
HAUK DB ${ }^{1}$, MAIA RF ${ }^{2}$ e RAMOS MJM ${ }^{3}$ \\ ${ }^{1}$ Centro Universitário FEI, Departamento de Engenharia Química \\ ${ }^{2}$ Centro Universitário FEI, Departamento de Ciência da Computação \\ ${ }^{3}$ Centro Universitário FEI, Departamento de Engenharia Química \\ E-mail para contato: dhauk@fei.edu.br
}

\begin{abstract}
RESUMO -O papel do docente é fundamental para unir novas tecnologias e o uso em atividades de ensino, de tal sorte a criar um ambiente para um aprendizado mais eficiente e duradouro, e que atenda também as expectativas dos discentes. Tendo em vista a gama de softwares disponíveis para diversos fins e que podem ser utilizados ou adaptados para o ensino, torna-se relevante avaliar como se apropriar de cada aplicação para se atingir objetivos educacionais, e avaliar se a aplicação contribuiu para o aprendizado, seja porque ofereceu mecanismos para auxiliar na transmissão do conteúdo por diversas formas e meios, permitindo ao professor trabalhar no seu tempo, em sala de aula com os estudantes, ou por outras razões que poderiam ser identificadas. Este trabalho utilizou um método misto baseado em aulas expositivas e aplicação do aprendizado baseado em problemas, na mesma aula, o uso de tecnologias de informação e comunicação $e$ simuladores para auxiliar estas aulas, disponibilizados no Moodle. A aplicação deste método nas aulas de química tecnológica do curso de Engenharia Mecânica do noturno e na disciplina de redes de computadores do curso de Ciência da Computação, mostrouse promissor, assim como, a utilização da taxonomia revisada de Bloom para avaliar o nível de aprendizado dos alunos no final de cada aula.
\end{abstract}

\section{INTRODUÇÃO}

Este trabalho teve como objetivo utilizar a metodologia de aprendizagem baseada em problemas (PBL), junto com as tecnologias da informação e comunicação (TIC), que foram previamente estudadas no trabalho de iniciação didática do aluno Vinícius Viva (2016), e avaliar o progresso dos alunos que utilizaram este método.

Entre muitas teorias e metodologias existentes na educação, a aprendizagem ativa tem grande potencial para unir métodos modernos de ensino e as TICs de forma a engajar os alunos em um aprendizado mais rico e duradouro. A aprendizagem ativa, que é definido por Grabinger e Dunlap (1995, p.5) como: “... o processo de engajar os alunos em um processo contínuo de colaboração na construção e aprimoramento do entendimento como uma consequência natural das experiências e interações autênticas com o mundo em torno deles". 


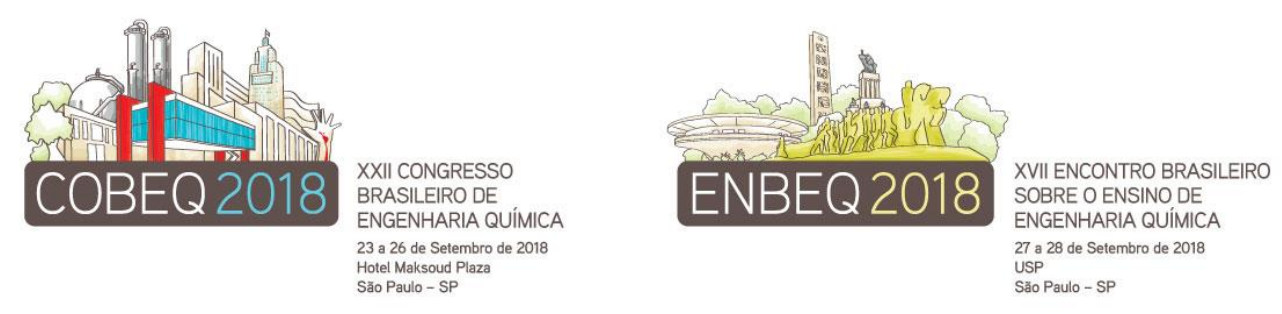

Dentro da aprendizagem ativa, temos a metodologia de aprendizagem baseada em problemas, definida por Bender $(2014$, p. 09$)$ como “... um modelo de ensino que consiste em permitir que os alunos confrontem as questões e os problemas do mundo real que consideram significativos, determinando como abordá-los e, então, agindo de forma cooperativa em busca de solução". Assim, por meio dessa definição, essa conduta metodológica foi usada como base para a construção deste trabalho.

\section{METODOLOGIA}

Pesquisou-se o estado da arte da aprendizagem baseada em problemas no Brasil e foi definido, qual o melhor método para aplicá-la em cursos de Engenharia e Ciências da Computação. As ferramentas estudadas no trabalho do aluno Vinícius Viva (2016) e utilizadas neste foram o Prezi, Powtoon, Ted-Edu, Scoopit, Wordpress, Dropbox, Polleverywhere, Kahoot e Proprofs, estas ferramentas foram disponibilizadas para o acesso dos alunos como links no Moodle, que foi utilizado como plataforma base para as TICs e para a interação entre aluno-aluno e aluno-professor no espaço virtual. Após a definição da metodologia de aprendizagem baseada em problema e com as TICs mencionadas, foram escolhidas duas disciplinas, uma do departamento de Engenharia Química que é lecionada para os alunos da Engenharia Mecânica, e outra do departamento de Ciências da Computação, onde alguns tópicos destas disciplinas foram selecionados para o preparo de materiais de apoio com as TICs e estes conteúdos foram aplicados em sala de aula utilizando a metodologia definida. A taxonomia revisada de Bloom forneceu os parâmetros de avaliação da aprendizagem de ambas as turmas de alunos.

A metodologia foi aplicada aos alunos da disciplina de Química Tecnológica, do curso de Engenharia Mecânica, em quatro aulas aplicadas em novembro de 2017. Na disciplina de Redes de Computadores do curso de Ciências da Computação, a metodologia de PBL foi aplicada com simuladores em todas as aulas, e no final do semestre de 2017 foi utilizada uma pesquisa com as TICs.

\subsection{Método escolhido e tecnologias de informação e comunicaçãa.}

Considerando as pesquisas sobre o PBL e a análise das aulas ministradas nos cursos da FEI, foi aplicado um método misto, incluindo uma parte expositiva e outra com o PBL, utilizouse um problema principal baseado nos tópicos que deveriam ser estudados, este problema foi estruturado de forma que o aluno precisasse estudar e aplicar o conteúdo. As aulas tinham início de forma expositiva com teoria, aproximadamente 30 minutos, onde o professor passou alguns pontos principais da matéria e os objetivos da aula foram pontuados, após esta primeira etapa os alunos estudaram pesquisando as TICs no Moodle ou consultando os colegas ou o professor. No final das aulas foram aplicados questionários com as ferramentas Polleverywhere ou Kahoot para avaliar o desempenho dos alunos segundo a taxonomia revisada de Bloom.

Como material de apoio, foram disponibilizados apresentações e vídeo aulas, preparadas com as TICs na disciplina de Química Tecnológica no Moodle. Foram utilizados os fóruns do Moodle como ferramenta de comunicação, onde os alunos podem conversar com o professor e outros alunos online. Para as avaliações, foram utilizadas as ferramentas Socriative, Polleverywhere, Kahoot e Proprofs. O Moodle foi estruturado de tal maneira que os alunos tivessem acesso a todo o material preparado com as TICs, considerando o fácil acesso dos alunos a esta plataforma. 

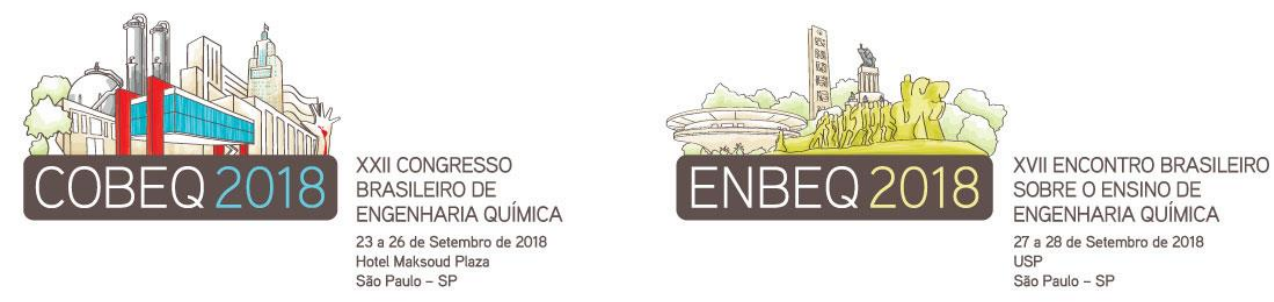

Já para as aulas de redes de computadores foram elaborados diversos conjuntos de simulações utilizando a aplicação Cisco Packet Tracer, cada uma representando uma situação esperada em casos reais e que os alunos deveriam ser capazes de entender e solucionar o problema apresentado.

\subsection{Avaliação com a Taxonomia revisada de Bloom.}

Bloom et. al. (1956) e seus colaboradores conduziram o desenvolvimento do estudo originando a Taxonomia de Bloom, que é considerada uma ferramenta utilizada para métodos avaliativos que tem como características básicas três domínios naturais do ser humano: efetivo (sentimento, comportamento, valores), psicomotor (percepção, habilidades físicas, comunicação não verbal) e a mais usada dentre todas, a cognitiva (aprender, desenvolvimento intelectual, dominar um conhecimento). Uma grande descoberta de Bloom et. al. (1956) foi que todos os alunos aprendiam, porém se diferenciavam na profundidade de absorção de conteúdo e com isso o domínio cognitivo foi a principal direção para a definição da taxonomia.

Dentro da taxonomia de Bloom são encontrados seis essenciais pilares, desde a mais simples até a mais complexa, de aprendizagem, na ordem crescente são lembrar, entender, aplicar, analisar, avaliar e por final criar.

Com base nesta taxonomia, foi utilizada a ideia de preparar perguntas para o final de cada aula, para poder avaliar o quanto o aluno aprendeu sobre o assunto da respectiva aula, cada pergunta abordava um pilar começando pelo mais simples, lembrar, até o mais avançado, criar.

\subsection{Aplicação do método na disciplina de Química Tecnológica.}

Em duas turmas compostas por um total de 95 alunos do curso de Engenharia Mecânica noturno do Centro Universitário da FEI, este método foi aplicado em quatro aulas do segundo semestre de 2017.

A primeira aula teve como foco a apresentação e discussão do problema principal, onde o professor começou a aula explicando aos seus alunos como iria funcionar as próximas aulas. Após toda orientação, o professor projetou o problema principal na lousa e seguidamente foi explicado como seria o desenvolvimento de cada etapa e como seria utilizado o conhecimento do primeiro trimestre no problema. Em seguida, mostrou como estava a organização dos materiais de apoio no Moodle e executou dois vídeos de curiosidades dos assuntos que seriam abordados nas próximas aulas, carregados nas TICs Youtube e Ted-Edu. No final da aula, o professor apresentou seis perguntas baseadas no Bloom, correspondente à aula dada com a ferramenta Polleverywhere, onde os alunos sincronizaram seus aparelhos móveis ao software e respondiam enquanto era projetado a porcentagem de acertos na lousa. A tabela 1 mostra a participação e acertos da primeira aula, com exceção da pergunta 2, as restantes tiveram boa taxa de acertos, indicando que os alunos entenderam os tópicos passados nesta primeira aula.

A segunda aula consistiu na teoria de Poder Calorífico, onde o professor abordou o assunto relacionado ao problema principal. Após algumas dicas para a resolução, deixou a turma livre para discutir a solução do problema em grupos enquanto estava disponível a tirar dúvidas. O desfecho da aula foi o questionário elaborado pelo professor para acompanhar o entendimento dos alunos, onde foi projetado a pergunta na lousa juntamente com as alternativas que os alunos iam respondendo diretamente de seu aparelho móvel, assim como na primeira 


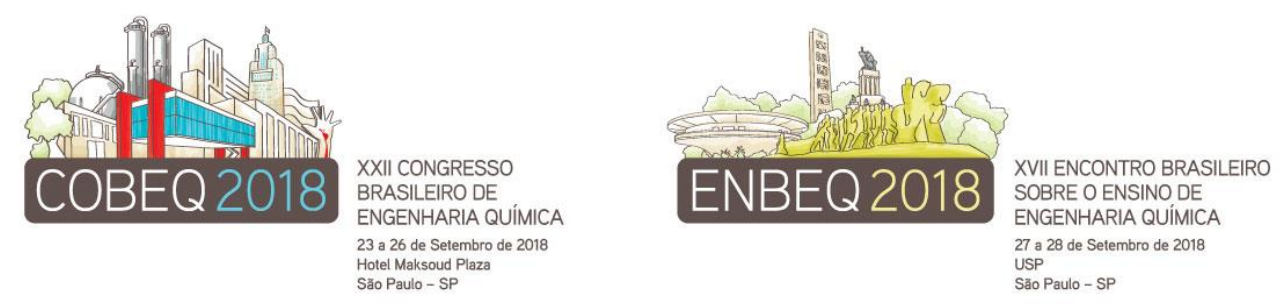

aula. A terceira e quarta aula seguiram o mesmo procedimento, sendo que na última foi feito uma análise e conclusão do problema principal.

\section{CONCLUSÕES}

Este trabalho utilizou a união da aprendizagem baseada em problemas com as TICs para desenvolver a motivação do aluno pela construção de seu próprio conhecimento e facilitar o processo ensino-aprendizagem. A aplicação do método PBL e do material preparado no Moodle, em sala de aula, mostrou-se eficiente para parte dos alunos, mas para este método, a participação do aluno fora de classe é essencial, constou-se que alguns alunos apenas aguardavam a aula e não faziam estudos extraclasse.

As ferramentas Polleverywhere e Kahoot, usadas para avaliação no final das aulas, mostraram que a aplicação da taxonomia revisada de Bloom pode ser uma forma de avaliar o quanto os alunos aprenderam no final de cada aula, desta forma o professor pode dar um feedback rápido aos alunos ou alterar sua aula para melhor a compreensão pelos mesmos.

Este método mostrou-se promissor, mas algumas melhorias podem ser feitas, como aplicar o método desde a primeira aula do semestre, refinar as perguntas baseadas na taxonomia revisada de Bloom, avaliar as respostas ao final de cada aula e ajustá-las visando melhorar os pontos fracos de cada turma.

\section{TABELAS}

Tabela 1: Porcentagem de acertos referente às seis perguntas apresentadas na primeira aula

\begin{tabular}{c|c|c|c}
\hline & $\begin{array}{c}\text { Número de alunos } \\
\text { que responderam }\end{array}$ & $\begin{array}{c}\text { Número de alunos que } \\
\text { acertaram a pergunta }\end{array}$ & $\begin{array}{c}\text { Porcentagem de } \\
\text { acerto }\end{array}$ \\
\hline Pergunta 1 & 13 & 13 & $100 \%$ \\
\hline Pergunta 2 & 14 & 9 & $29 \%$ \\
\hline Pergunta 3 & 15 & 14 & $93 \%$ \\
\hline Pergunta 4 & 15 & 15 & $88 \%$ \\
\hline Pergunta 5 & 17 & 15 & $86 \%$ \\
\hline Pergunta 6 & 14 & 12 & \\
\hline
\end{tabular}

Fonte: Autores

\section{REFERÊNCIAS}

BLOOM, B. S., HASTINGS, J. T., \& MADAUS, G. F. (1956). Handbook on formative and summative evaluation of student learning. New York: McGaw-Hill.

BENDER, William N. Aprendizagem baseada em projetos: Educação diferenciada para o século XXI. Penso editora, 2014.

GRABINGER, R. Scott; DUNLAP, Joanna C. Rich environments for active learning: A definition. Research in learning Technology, v. 3, n. 2, 1995. 

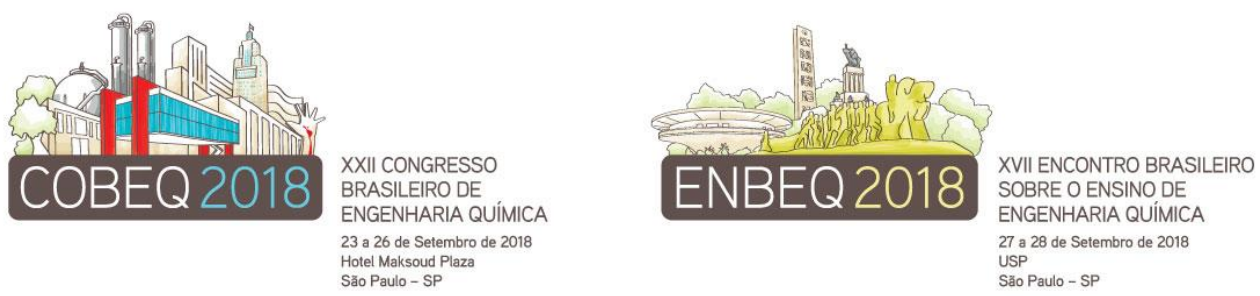

VIVA, Vinícius. Compilação e estudo sobre o uso de Tecnologias de Informação e Comunicação em sala de aula. Centro Universitário FEI, 2016. Disponível em: http://moodle.fei.edu.br/moodle/course/view.php?id=449. Acessado em 21 de dezembro de 2016 